\title{
Dominant climatic factors driving annual runoff changes at the catchment scale across China
}

\author{
Zhongwei Huang ${ }^{1,2,3}$, Hanbo Yang ${ }^{1}$, and Dawen Yang ${ }^{1}$ \\ ${ }^{1}$ State Key Laboratory of Hydro-Science and Engineering, Department of Hydraulic Engineering, Tsinghua University, \\ Beijing 100084, China \\ ${ }^{2}$ Key Laboratory of Water Cycle and Related Land Surface Processes, Institute of Geographic Sciences and Natural \\ Resources Research, Chinese Academy of Sciences, Beijing 100101, China \\ ${ }^{3}$ University of Chinese Academy of Sciences, Beijing 100049, China
}

Correspondence to: Hanbo Yang (yanghanbo@tsinghua.edu.cn)

Received: 13 November 2015 - Published in Hydrol. Earth Syst. Sci. Discuss.: 15 December 2015

Revised: 1 June 2016 - Accepted: 10 June 2016 - Published: 4 July 2016

\begin{abstract}
With global climate changes intensifying, the hydrological response to climate changes has attracted more attention. It is beneficial not only for hydrology and ecology but also for water resource planning and management to understand the impact of climate change on runoff. In addition, there are large spatial variations in climate type and geographic characteristics across China. To gain a better understanding of the spatial variation of the response of runoff to changes in climatic factors and to detect the dominant climatic factors driving changes in annual runoff, we chose the climate elasticity method proposed by Yang and Yang (2011). It is shown that, in most catchments of China, increasing air temperature and relative humidity have negative impacts on runoff, while declining net radiation and wind speed have positive impacts on runoff, which slow the overall decline in runoff. The dominant climatic factors driving annual runoff are precipitation in most parts of China, net radiation mainly in some catchments of southern China, air temperature and wind speed mainly in some catchments in northern China.
\end{abstract}

\section{Introduction}

Climate change has become increasingly significant, and it has important impacts on the hydrological cycle and water resource management. Changes in climatic factors and runoff have been observed in many different regions of China. Reductions in precipitation occurred in the Hai River basin, the upper reaches of the Yangtze River basin, and the Yellow River basin, and an increase occurred in western China (Yang et al., 2014a). A $29 \%$ decline in surface wind speed occurred in China during 1966-2011 (Liu et al., 2014). Most of the river basins in north China have exhibited an obvious decline in mean annual runoff, such as the Shiyang River basin (Ma et al., 2008), the Yellow River basin (Yang et al., 2004; Tang et al., 2007; Cong et al., 2009), the Hai River basin (Ma et al., 2010), and the Han River basin (Sun et al., 2014). The hydrologic processes have been influenced by different climatic factors. For example, a decline in land surface wind speed can lead to a decrease in evapotranspiration, and changes in precipitation may affect water generation and concentration. However, the dominant climatic factor driving annual runoff change is still unknown in many catchments in China.

There are several approaches to investigate the impacts of annual runoff on climate change, including hydrologic models (Yang et al., 1998; Arnold et al., 1998; Yang et al., 2000; Arnold and Fohrer, 2005), the climate elasticity method (Schaake, 1990; Sankarasubramanian et al., 2001), and the statistics method (Vogel et al., 1999). The climate elasticity method, which has the advantage of requiring only the mean and trend of climate and basin variables and not requiring extensive historical measurements, was widely used in quantifying the effects of climatic factors on runoff, such as in the Yellow River basin (Zheng et al., 2009; Yang and Yang, 2011), the Luan River basin (Xu et al., 2013), the Chao-Bai River basin (Ma et al., 2010), and the Hai River basin (Ma et al., 2008; Yang and Yang, 2011). 
A simple climate elasticity method was first defined by Schaake (1990) to estimate the impacts of precipitation $(P)$ on annual runoff $(R)$ :

$\frac{d R}{R}=\varepsilon_{\mathrm{P}}(P, R) \frac{d P}{P}$,

where $\varepsilon_{\mathrm{P}}$ is the precipitation elasticity. To consider the effects of precipitation and air temperature on runoff, $\mathrm{Fu}$ et al. (2007) calculated the runoff change as

$\frac{d R}{R}=\varepsilon_{a} \frac{d P}{P}+\varepsilon_{b} \frac{\mathrm{d} T}{T}$,

where $\varepsilon_{a}$ and $\varepsilon_{b}$ are the precipitation elasticity and air temperature elasticity, respectively.

Five categories of methods can be used to estimate climate elasticity (Sankarasubramanian et al., 2001). The analytical derivation method has been widely used in many studies because it is clear in theory and does not need a large amount of historical observed data. Arora (2002) proposed an equation to calculate the response of runoff to precipitation and potential evaporation:

$\frac{\Delta R}{R}=\left[1+\frac{\phi F_{0}^{\prime}(\phi)}{1-F_{0}(\phi)}\right] \frac{\Delta P}{P}-\frac{\phi F_{0}^{\prime}(\phi)}{1-F_{0}(\phi)} \frac{\Delta E}{E}$,

where $\phi=E / P$ and $F_{0}(\phi)$ is a Budyko formula and $F_{0}^{\prime}(\phi)$ is the derivation of $\phi$. The climate elasticity of runoff was evaluated in the upper reaches of the Yellow River basin by using Eq. (3) (Zheng et al., 2009). To evaluate the impacts from other climatic factors, Yang and Yang (2011) proposed an analytical method, based on the Penman equation (Penman, 1948) and the annual water balance equation, to quantify the runoff change relative to changes in different climatic factors. By taking advantage of the mean annual climatic factors in the study period, the runoff elasticity to precipitation $(P)$, air temperature $(T)$, net radiation $\left(R_{\mathrm{n}}\right)$, relative humidity $(\mathrm{RH})$, and wind speed $\left(U_{2}\right)$ were derived. The runoff change can be expressed as follows:

$\frac{d R}{R}=\varepsilon_{\mathrm{P}} \frac{d P}{P}+\varepsilon_{R_{\mathrm{n}}} \frac{d R_{\mathrm{n}}}{R_{\mathrm{n}}}+\varepsilon_{T} \mathrm{~d} T+\varepsilon_{U_{2}} \frac{d U_{2}}{U_{2}}+\varepsilon_{\mathrm{RH}} \frac{d \mathrm{RH}}{\mathrm{RH}}$,

where $\varepsilon_{\mathrm{P}}, \varepsilon_{R_{\mathrm{n}}}, \varepsilon_{T}, \varepsilon_{U_{2}}$, and $\varepsilon_{\mathrm{RH}}$ are the runoff elasticity relative to precipitation $(P)$, net radiation $\left(R_{\mathrm{n}}\right)$, mean air temperature $(T)$, wind speed $\left(U_{2}\right)$, and relative humidity $(\mathrm{RH})$, respectively. However, this method was only tested in several catchments in non-humid north China.

There are large spatial variations in both geographic characteristics and climate types across China, resulting in a large variation in the hydrologic response to climate change. Therefore, the current study aims to (1) further validate the method proposed by Yang and Yang (2011), (2) evaluate the climate elasticity of climatic factors to runoff at the catchment scale across China, and (3) estimate the contribution of climatic factors to runoff change and then detect the dominant climatic factor driving annual runoff change.

\section{Climate elasticity method based on the Budyko hypothesis}

At the catchment scale, there is a relationship of evaporation with available water and available energy, referred as the Budyko hypothesis (Budyko, 1961). Budyko defined the available energy as the water equivalent of net radiation $R_{\mathrm{n}}$ at a large spatial scale. However, at a small spatial scale, with the exception of net radiation, the energy imported by horizontal advection will affect water and energy balances. The effects of the horizontal advection can be exposed by climatic factors, such as humidity and air temperature. At the same time, this effect of net radiation and these climatic factors can be estimated by potential evaporation. Therefore, Yang et al. (2008) chose potential evaporation to represent available energy and further derived an analytical equation of the Budyko hypothesis as follows:

$E=\frac{E_{0} P}{\left(P^{n}+E_{0}^{n}\right)^{1 / n}}$,

where the parameter $n$ represents the characteristics of the catchment, such as land use and coverage change, vegetation, slopes, and climate seasonality (Yang et al., 2014a). The water balance equation can be simplified as $P=E+R$ at the catchment scale for a long term, so runoff can be expressed as follows:

$R=P-\frac{E_{0} P}{\left(E_{0}^{n}+P^{n}\right)^{1 / n}}$.

To attribute the contribution of changes in $P$ and $E_{0}$ to runoff, Yang and Yang (2011) derived a new equation:

$\frac{d R}{R}=\varepsilon_{1} \frac{d P}{P}+\varepsilon_{2} \frac{d E_{0}}{E_{0}}$,

where $\varepsilon_{1}$ and $\varepsilon_{2}$ are the climate elasticity of runoff relative to $P$ and $E_{0}$, respectively; they can be estimated as $\varepsilon_{1}=$ $\frac{(1-\partial E \partial P) P}{P-E}$ and $\varepsilon_{2}=-\frac{\partial E \partial E_{0}}{P-E}$. The potential evaporation $E_{0}$ $\left(\mathrm{mm} \mathrm{day}^{-1}\right)$ can be evaluated by the Penman equation (Penman, 1948):

$E_{0}=\frac{\Delta}{\Delta+\gamma}\left(R_{\mathrm{n}}-G\right) / \lambda+\frac{\gamma}{\Delta+\gamma}$
$6.43\left(1+0.536 U_{2}\right)(1-\mathrm{RH}) e_{\mathrm{s}} / \lambda$,

and the physical meanings of these symbols are shown in Table 1.

Similar to Eq. (7), the response of potential evaporation to climatic factors can be estimated as

$\frac{d E_{0}}{E_{0}}=\varepsilon_{3} \frac{d R_{\mathrm{n}}}{R_{\mathrm{n}}}+\varepsilon_{4} \mathrm{~d} T+\varepsilon_{5} \frac{d U_{2}}{U_{2}}+\varepsilon_{6} \frac{d \mathrm{RH}}{\mathrm{RH}}$,

where $\varepsilon_{3}, \varepsilon_{4}, \varepsilon_{5}, \varepsilon_{6}$ are the elasticity of potential evaporation relative to net radiation, air temperature, wind speed, and relative humidity, respectively. Therefore, $\varepsilon_{3}=\frac{R_{\mathrm{n}}}{E_{0}} \frac{\partial E_{0}}{\partial R_{\mathrm{n}}}$, 
Table 1. Principal parameters of the Penman equation.

\begin{tabular}{llll}
\hline Symbol & Unit & Value & Physical meaning \\
\hline$\Delta$ & $\mathrm{kPa}^{\circ} \mathrm{C}^{-1}$ & - & Slope of the saturated vapor pressure vs. air temperature curve \\
$R_{\mathrm{n}}$ & $\mathrm{MJ} \mathrm{m}^{-2} \mathrm{~d}^{-1}$ & - & Net radiation \\
$G$ & $\mathrm{MJ} \mathrm{m}^{-2} \mathrm{~d}^{-1}$ & - & Soil heat flux \\
$\gamma$ & $\mathrm{kPa}^{\circ} \mathrm{C}^{-1}$ & - & Psychrometric constant \\
$\lambda$ & $\mathrm{MJ} \mathrm{kg}^{-1}$ & 2.45 & Latent heat of vaporization \\
$e_{\mathrm{S}}$ & $\mathrm{kPa}_{\mathrm{RH}}$ & - & Saturated vapor pressure \\
$U_{2}$ & $\mathrm{~m} \mathrm{~s}^{-1}$ & - & Relative humidity \\
\hline
\end{tabular}

$\varepsilon_{4}=\frac{1}{E_{0}} \frac{\partial E_{0}}{\partial T}, \varepsilon_{5}=\frac{U_{2}}{E_{0}} \frac{\partial E_{0}}{\partial U_{2}}$, and $\varepsilon_{6}=\frac{\mathrm{RH}}{E_{0}} \frac{\partial E_{0}}{\partial \mathrm{RH}}$. Due to the complex relationship between $E_{0}$ and $T$, the value of $\frac{\partial E_{0}}{\partial T}$ was calculated by the finite difference method, while $\frac{\partial E}{\partial P}, \frac{\partial E}{\partial E_{0}}$, $\frac{\partial E_{0}}{\partial R_{\mathrm{n}}}, \frac{\partial E_{0}}{\partial U_{2}}$, and $\frac{\partial E_{0}}{\partial \mathrm{RH}}$ were calculated by the finite differential method.

Yang and Yang (2011) substituted Eq. (9) into Eq. (7), yielding the following:

$\frac{d R}{R}=\varepsilon_{1} \frac{d P}{P}+\varepsilon_{2} \varepsilon_{3} \frac{d R_{\mathrm{n}}}{R_{\mathrm{n}}}+\varepsilon_{2} \varepsilon_{4} \mathrm{~d} T+\varepsilon_{2} \varepsilon_{5} \frac{d U_{2}}{U_{2}}+\varepsilon_{2} \varepsilon_{6} \cdot \frac{d \mathrm{RH}}{\mathrm{RH}}$.

Equation (10) was denoted as follows:

$R^{*}=P^{*}+R_{\mathrm{n}}^{*}+T^{*}+U_{2}^{*}+\mathrm{RH}^{*}$,

where $P^{*}, R_{\mathrm{n}}^{*}, T^{*}, U_{2}^{*}$, and $\mathrm{RH}^{*}$ symbolize the runoff changes caused by the changes in $P, R_{\mathrm{n}}, T, U_{2}$, and $\mathrm{RH}$, respectively. The largest one among them is considered as the dominant climatic factor driving annual runoff change.

\section{Data and method}

\subsection{Study region and data}

The catchment information data set was collected from the Ministry of Water Resources of the People's Republic of China (Water Resources and Hydropower Planning and Design General Institute, 2011). In the data set, the catchment boundary and runoff ratio were available. Chinese water resources zoning was divided by level as follows: there are 10 first-level basins, 80 second-level river basins, and 210 thirdlevel river basins (shown in Fig. 1a). There are no observed meteorological data on Taiwan Island and no runoff in two inland catchments in Xinjiang province. Hence, 207 thirdlevel catchments were selected in this study.

The meteorological data, obtained from 736 weather stations between 1961 and 2010 from the China Meteorological Administration (CMA), included precipitation, surface mean air temperature, maximum air temperature, minimum air temperature, relative humidity, sunshine hours, and wind speed. In addition, daily solar radiation during the period 1961-2010 was collected from 118 weather stations.
To obtain the annual climatic factors in each catchment, first, a $10 \mathrm{~km}$ grid covering the study area was prepared. Second, we interpolated the observed data of the meteorological stations into a grid. The interpolation method used for climatic factors was an inverse-distance weighted technique, except air temperature, which must consider the influence of elevation (Yang et al., 2006). Third, according to the $10 \mathrm{~km}$ grid data set, the average values of climatic factors of each catchment were calculated.

Because only 118 weather stations directly measured solar radiation, the daily net radiation $R_{\mathrm{n}}\left(\mathrm{MJ} \mathrm{m}^{-2} \mathrm{day}^{-1}\right)$ was calculated by an empirical formulation (Allen et al., 1998):

$$
\begin{aligned}
& R_{\mathrm{n}}=\left(1-\alpha_{\mathrm{s}}\right) R_{\mathrm{s}}-\sigma\left[\frac{\left(T_{\max }+273.15\right)^{4}+\left(T_{\min }+273.15\right)^{4}}{2}\right] \\
& \left(0.1+0.9 \frac{n}{N}\right) \times\left(0.34-0.14 \sqrt{\frac{\mathrm{RH}}{100} e_{\mathrm{s}}}\right.
\end{aligned}
$$

The physical meaning of these symbols are shown in Table 2 . $R_{\mathrm{S}}$ was calculated by using the Angström formulation (Angström, 1924):

$R_{\mathrm{s}}=\left(a_{\mathrm{s}}+b_{\mathrm{s}} \times \frac{n}{N}\right) R_{a}$,

where $R_{a}$ is extraterrestrial radiation, and $a_{\mathrm{s}}$ and $b_{\mathrm{s}}$ are parameters that were calibrated using the data at the 118 stations with solar radiation observations (Yang et al., 2006). In Eq. (12), $e_{\mathrm{s}}$ is estimated as

$e_{\mathrm{s}}=0.3054\left[\exp \left(\frac{17.27 T_{\max }}{T_{\max }+237.3}\right)+\exp \left(\frac{17.27 T_{\min }}{T_{\min }+237.3}\right)\right]$.

The wind speed at the height of $2 \mathrm{~m}\left(U_{2}, \mathrm{~m} \mathrm{~s}^{-1}\right)$ was estimated from a logarithmic wind profile based on the observed wind speed at the height of $10 \mathrm{~m}$ (Allen et al., 1998):

$U_{2}=U_{z} \frac{4.87}{\ln (67.8 z-5.42)}=0.75 U_{10}$.

Based on Eq. (6), the runoff ratio $(\alpha)$ can be estimated as follows:

$\alpha=\frac{R}{P}=1-\frac{E_{0}}{\left(E_{0}^{n}+P^{n}\right)^{1 / n}}$. 


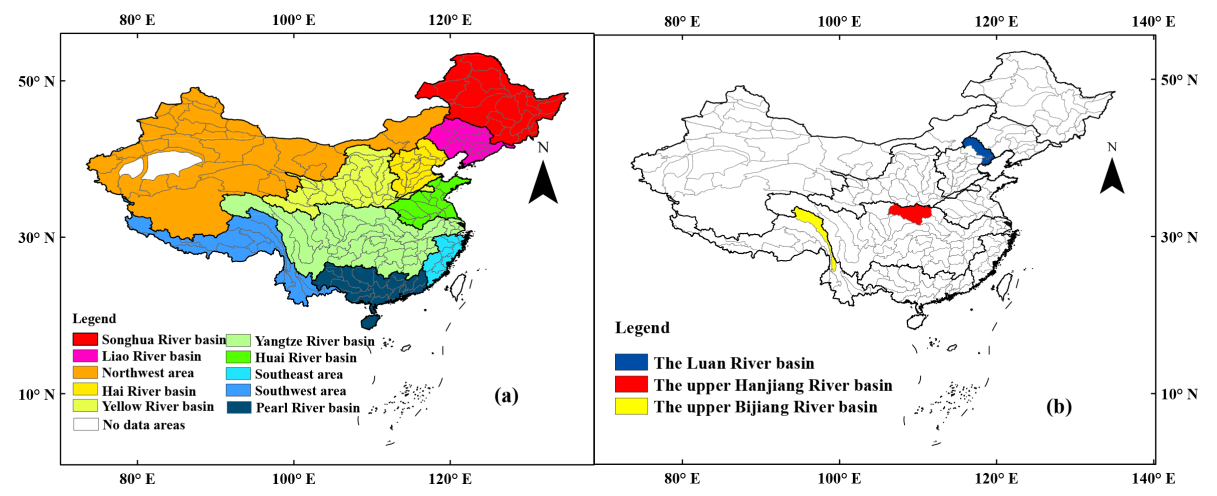

Figure 1. (a) Spatial distribution of third-level river basins in China and (b) three catchments for validation.

Furthermore, the catchment characteristics parameter $n$ was calculated according to $\alpha, E_{0}$, and $P$.

\subsection{Validation of the climate elasticity method}

Two steps were taken for the validation of the climate elasticity method, namely validating Eq. (7) and validating Eq. (9).

A catchment in a humid region with observed data for annual precipitation, annual potential evaporation, and annual runoff from 1956 to 2000 was chosen to validate Eq. (7), namely the Upper Bijiang River basin (shown in Fig. 1b). The Upper Bijiang River basin is located in the upper reaches of the Lancang River basin, with $495 \mathrm{~mm}$ mean annual precipitation and $243 \mathrm{~mm}$ mean annual runoff. The results given by Eq. (7) were compared with the observed results. This approach is reasonable because this catchment is located in the southwest mountainous region, where there is no remarkable impact from human activities. However, in most regions, both anthropogenic activities and climate change have become important factors driving runoff change, and observed runoff data include the effects not only from anthropogenic activities but also from climate change. Therefore, we additionally collected the modeled runoff change and the contribution from climate change for another two catchments from the literature, to validate the climate elasticity method, namely the Luan River basin and the Upper Hanjiang River basin (shown in Fig. 1b). The Luan River basin, located in north China, is a part of the Hai River basin. It has a mean annual precipitation of $455 \mathrm{~mm}, 75-85 \%$ of which falls from June to September. The Upper Hanjiang River basin, lying in the middle and lower reaches of the Yangtze River basin, finally flows into the Danjiangkou Reservoir. In the two catchments, runoff undergoes a remarkable change, and the causes for this runoff change were analyzed using hydrological models. Xu et al. (2013) assessed the response of annual runoff to anthropogenic activities and climate change in the Luan River basin by using the geomorphology-based hydrological model (GBHM). Sun et al. (2014) explored the contributions from climate change and variation of catchment properties variation to runoff change in the Upper Han- jiang River basin using three different methods: climate elasticity, decomposition, and dynamic hydrological modeling methods (i.e., THREW model, Tian et al., 2006; Mou et al., 2008). To validate the climate elasticity method, the results given by Eq. (7) were compared with the results in the references.

Equation (9) is the first-order Taylor approximation of the Penman equation. We first evaluated the climate elasticity of potential evaporation relative to air temperature, net radiation, relative humidity, and wind speed, as well as the change in these climatic factors, and we further estimated the change in potential evaporation according to Eq. (9), denoted as $E_{0}^{*}$. On the other hand, we calculated the potential evaporation change $\left(E_{0}^{* *}\right)$ as

$E_{0}^{* *}=\frac{f\left(T+\mathrm{d} T, R_{\mathrm{n}}+d R_{\mathrm{n}}, U_{2}+d U_{2}, \mathrm{RH}+d \mathrm{RH}\right)-f\left(T, R_{\mathrm{n}}, U_{2}, \mathrm{RH}\right)}{E_{0}}$,

where the function $f($ ) represents the Penman equation. Then, the first approximation $E_{0}^{*}$ was compared with $E_{0}^{* *}$, and the relative error was defined as follows: $\mathrm{RE}=\left(E_{0}^{*}-\right.$ $\left.E_{0}^{* *}\right) / E_{0}^{* *}$, which was an effective criterion to assess Eq. (9). In addition, the data of annual climatic factors in 207 catchments, which were interpolated from the meteorological station observations, were used for validation.

\subsection{Trend analysis}

The Mann-Kendall (MK) nonparametric test (Kendall, 1948, 1990) is an effective statistical tool for trend detection, especially for hydrological and meteorological time series (Maidment, 1993). The MK nonparametric test is widely used for its convenient calculation processes. The sample data are not necessary to obey some specific distribution, but they must be serially independent. In this study, we first evaluated the significance levels of the trend of the hydrological and meteorological time series which were set at 0.05 and 0.1 , and then estimated the slope of the trend:

$\beta=\operatorname{median}\left[\frac{\left(x_{j}-x_{i}\right)}{(j-i)}\right]$, 
Table 2. Principal parameters of Eq. (12).

\begin{tabular}{llll}
\hline Symbol & Unit & Value & Physical meaning \\
\hline$\alpha_{\mathrm{S}}$ & Dimensionless & - & Albedo or the canopy reflection coefficient \\
$R_{\mathrm{S}}$ & $\mathrm{MJ} \mathrm{m}^{-2} \mathrm{day}^{-1}$ & - & Solar radiation \\
$\sigma$ & $\mathrm{MJ} \mathrm{K}^{-4} \mathrm{~m}^{-2} \mathrm{day}^{-1}$ & $4.903 \times 10^{-9}$ & Stefan-Boltzmann constant \\
$T_{\max }$ & ${ }^{\circ} \mathrm{C}$ & - & Daily maximum air temperature \\
$T_{\min }$ & ${ }^{\circ} \mathrm{C}$ & - & Daily minimum air temperature \\
$n$ & hour & - & Daily actual sunshine duration \\
$N$ & hour & - & Daily maximum possible duration of sunshine \\
$\mathrm{RH}$ & $\%$ & - & Daily relative humidity \\
\hline
\end{tabular}

for all $i<j$, where $\beta$ is the magnitude of trend, $\beta>0$ indicates an increasing trend, and $\beta<0$ indicates a decreasing trend.

\section{Results}

\subsection{Validation of the climate elasticity method}

Table 3 shows the comparisons of runoff change, which were assessed by the climate elasticity method, the hydrological models, and the observed data. The runoff changes were 6.9 and $8.4 \%$ in the Upper Bijiang River basin, -21.4 and $-30.8 \%$ in the Upper Luan River basin, 9.1 and $-31.4 \%$ in the Lower Luan River basin, and -19.0 and $-27.6 \%$ in the Upper Hanjiang River basin, as evaluated by the climate elasticity method and the observed data, respectively. The results evaluated by the climate elasticity method performed well in comparison with the observed data in these basins except for the Lower Luan River basin, where anthropogenic heterogeneity, such as irrigation and reservoir operation, may be important factors driving runoff change. Conversely, the climate contribution to runoff was -14 and $-21.4 \%$ in the Upper Luan River basin, 12.4 and $9.1 \%$ in the Lower Luan River basin, and -19.6 and $-19.0 \%$ in the Upper Hanjiang River basin, as estimated by the climate elasticity method and the hydrological models, respectively. These results were as expected and may provide an effective assessment of runoff change without consideration of anthropogenic heterogeneity, making it possible to use the climate elasticity method to evaluate climate elasticity and the response of runoff to climate change both in humid and arid catchments.

Figure $2 \mathrm{a}$ shows the relationship between the potential evaporation change evaluated by Eq. (9) and that evaluated by Eq. (17), with most of the points falling around the line $y=x$. The relative error (RE) (shown in Fig. 2b) mostly ranged from -3 to $1 \%$. A high correlation and small relative errors show the accuracy of Eq. (9), making it possible to express potential evaporation change as a function of the variation of climatic factors. (a)
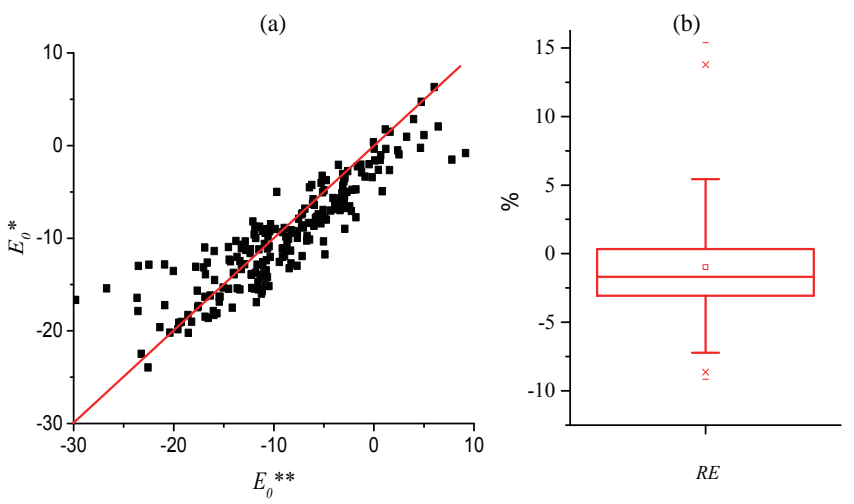

Figure 2. (a) Comparison between the potential evaporation change evaluated by Eq. (9), denoted as $E_{0}^{*}(\%)$, and that evaluated by Eq. (17), denoted as $E_{0}^{* *}(\%)$, from 1961 to 2010, and (b) the relative error (RE) $(\%)$ caused by the first-order approximation, where $\mathrm{RE}=\left(E_{0}^{*}-E_{0}^{* *}\right) / E_{0}^{* *}, E_{0}^{*}$, and $E_{0}^{* *}$ were the potential evaporation changes evaluated by Eqs. (9) and (17), respectively.

\subsection{The mean annual climatic factors}

The mean annual precipitation, net radiation, air temperature, wind speed, and relative humidity for each catchment between 1961 and 2010 are shown in Fig. 3. The mean annual precipitation in China, which had a typical spatial variation that decreased from the southeast to the northwest, ranged from $30 \mathrm{~mm}$ in the northwest inland to $1883 \mathrm{~mm}$ in the southeast coastal area. The net radiation differed from 3 to 10 $\left(\mathrm{MJ} \mathrm{m}^{-2} \mathrm{~d}^{-1}\right)$ in China, of which the largest value occurred in the Qinghai-Tibet Plateau and the lowest value occurred in the Sichuan Basin. The mean annual air temperature in China had a range of $-3.3-23.8^{\circ} \mathrm{C}$, with a typical spatial variation of decrease from the south to the north. The wind speed at a $2 \mathrm{~m}$ height in China ranged from 1 to $4 \mathrm{~m} \mathrm{~s}^{-1}$, with the highest value occurring in the north and the coastline and the lowest value occurring in the Sichuan Basin. The relative humidity, which ranged from $35 \%$ in the northwest to $82 \%$ in the southeast, had a positive correlation with the precipitation. According to Eq. (6), we can evaluate the mean annual runoff (shown in Fig. 3f). The annual mean runoff had 
Table 3. Validation of the climate elasticity method.

\begin{tabular}{lllll}
\hline Catchments & Upper Bijiang River basin & Upper Luan River basin & Lower Luan River basin & Upper Hanjiang River basin \\
\hline Study period & $1956-2000$ & $1956-2005$ & $1956-2005$ & $1970-2000$ \\
$\bar{P}$ & 495.2 & 402.4 & 512.4 & 850.0 \\
$\overline{E_{0}}$ & 1056.9 & 1257.4 & 1207.5 & 1178.0 \\
$\overline{R_{0}}$ & 243.4 & 34 & 92.6 & 352 \\
$\Delta P / \bar{P}$ & $3.9 \%$ & $-9.8 \%$ & $1.8 \%$ & $-11.3 \%$ \\
$\Delta E_{0} / \overline{E_{0}}$ & $-3.7 \%$ & $-6.2 \%$ & $-8.0 \%$ & $3.0 \%$ \\
$\Delta R$ & 20.5 & -10.1 & -29.1 & -97.0 \\
$(\Delta R / R)_{\mathrm{O}}$ & $8.4 \%$ & $-30.8 \%$ & $-31.4 \%$ & $-27.6 \%$ \\
$n$ & 0.7 & 1.4 & 1.4 & 1.0 \\
$\varepsilon_{\mathrm{P}}$ & 1.39 & 2.2 & 2.1 & 1.6 \\
$\varepsilon_{E_{0}}$ & -0.39 & -1.2 & -1.1 & -0.6 \\
$(\Delta R / R)_{\mathrm{M}}$ & - & $-14.0 \%$ & $12.4 \%$ & $-19.6 \%$ \\
$(\Delta R / R)_{\mathrm{E}}$ & $6.9 \%$ & $-21.4 \%$ & $9.1 \%$ & $-19.0 \%$ \\
\hline
\end{tabular}

$* \bar{P}$ is the mean annual precipitation $(\mathrm{mm}) ; \overline{E_{0}}$ is mean annual potential evaporation $(\mathrm{mm}) ; \overline{R_{0}}$ is mean annual runoff $(\mathrm{mm}) ; \Delta P / \bar{P}$ is the percentage of precipitation change $(\%) ; \Delta E_{0} / \overline{E_{0}}$ is the percentage of potential evaporation change; $\Delta R$ is the runoff change during the study period $(\mathrm{mm}) ;(\Delta R / \bar{R})_{\mathrm{O}}$ is the percentage of runoff change that was observed; $n$ is the characteristics parameter; $\varepsilon \mathrm{P}$ and $\varepsilon_{E_{0}}$ are the precipitation elasticity and potential evaporation elasticity, respectively; $(\Delta R / R)_{\mathrm{M}}$ and $(\Delta R / R)_{\mathrm{E}}$ are the percentage of runoff change that was estimated by hydrological models and the climate elasticity method, respectively.

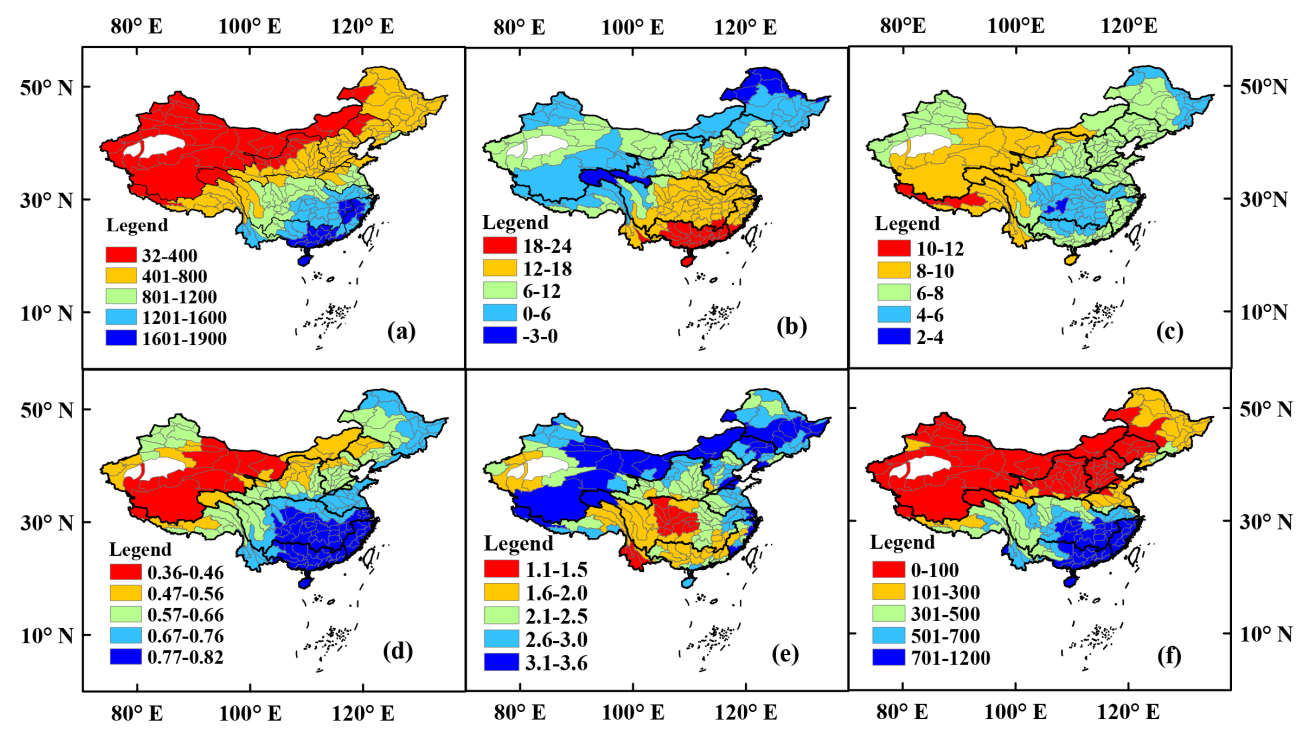

Figure 3. The mean annual (a) precipitation (unit: $\mathrm{mm}$ ), (b) air temperature (unit: ${ }^{\circ} \mathrm{C}$ ), (c) net radiation (unit: $\mathrm{MJ} \mathrm{m}^{-2} \mathrm{~d}^{-1}$ ), $(\mathbf{d})$ relative

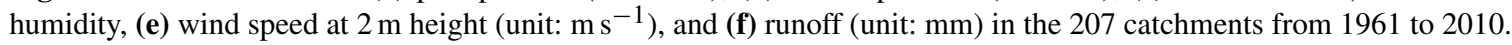

a range of $0-1176 \mathrm{~mm}$, exhibiting a similar spatial variation with that of precipitation.

\subsection{Climate elasticity of the 207 catchments}

Figure 4 shows the climate elasticity of runoff to the climatic factors for each catchment. In the 207 catchments, precipitation elasticity $\varepsilon_{\mathrm{p}}$ ranged from 1.1 to 4.75 (2.0 on average), indicating that a $1 \%$ change in precipitation leads to a $1.1-4.75 \%$ change in runoff. The lowest value of $\varepsilon_{\mathrm{p}}$, ranging from 1.1 to 1.5 , occurred in southern China. The highest value of $\varepsilon_{\mathrm{p}}$ mostly occurred in the Huai River basin, the Liao River basin, and the Hai River basin, and the lower reaches of Yellow River basin, indicating the highest sensitivity of runoff to precipitation change in these regions.

A $1 \% R_{\mathrm{n}}$ change may result in $-2.1-0 \%(-0.5$ on average) runoff change. The high value of $-2.1<\varepsilon_{R_{\mathrm{n}}}<-0.8$ mostly occurred in the Huai River basin, the Hai River basin, and the lower reaches of the Yellow River basin, while the relatively small value of $-0.4<\varepsilon_{R_{\mathrm{n}}}<0$ mostly occurred in southern and northwest China.

The air temperature elasticity, ranging from -0.002 decade $^{-1}$ to -0.095 decade $^{-1}\left(-0.025\right.$ decade $^{-1}$ on average), indicates that a $1{ }^{\circ} \mathrm{C}$ increase in air temperature may result in a $0.2-9.5 \%$ decrease in runoff. The high 
value of -0.095 decade $^{-1}<\varepsilon_{T}<-0.026$ decade $^{-1}$ mainly occurred in the Songhua River basin, the Liao River basin, the Hai River basin, the lower reaches of the Yellow River basin, and the east part of the northwest area, while a small value of $-0.025 \mathrm{decade}^{-1}<\varepsilon_{T}<-0.00 \mathrm{decade}^{-1}$ mainly occurred in the south and west regions of China. The absolute value of air temperature elasticity was small when compared with other elasticities, the reason for which will be discussed in the Appendix.

The value of $\varepsilon_{U_{2}}$ ranged from -0.01 to $-0.94(-0.22$ on average). The high value of $-0.95<\varepsilon_{\mathrm{RH}}<-0.5$ mostly occurred in the Yellow River basin, the Huai River basin, the Hai River basin, and the Liao River basin, indicating that a $1 \%$ wind speed decrease will lead to a $0.5-0.95 \%$ decline in runoff.

The value of $\varepsilon_{\mathrm{RH}}$ ranged from 0.05 to 3 ( 0.74 on average), and the spatial distributions of these values were similar to those of precipitation.

\subsection{Changes in the climatic factors}

Changes in climatic factors are shown in Fig. 5. Significance and rate of changes in climatic factors from 1961 to 2010 have been reported by Yang et al. (2015). There is a large spatial variation in precipitation change which increased in northwest China (ranging from 5 to $11 \%$ decade $^{-1}, p<0.05$ ) and decreased in the Yellow River basin, the Hai River basin, and the upper reach of the Yangtze River basin (ranging from -5 to $-2.5 \%$ decade $^{-1}, p<0.05$ ), but there were no significant change trend shown in 130 catchments of the total 207 catchments.

Net radiation showed a decrease in most catchments. Large decrease (ranging from -6 to $-3 \%$ decade $^{-1}$ ) occurred in the Hai River basin, the Huai River basin, and the lower reach of Yangtze River basin $(p<0.05)$, while small decrease (ranging from -3 to $-0 \%$ decade $^{-1}$ ) occurred in the majority of northern China. No significant change trend was shown in the Qinghai-Tibet Plateau.

Air temperature increased all over China. A large increase (ranging from 0.4 to $0.8^{\circ} \mathrm{Cdecade}^{-1}$ ) mainly occurred in northern China $(p<0.05)$, while a small decrease (ranging from 0 to $0.4{ }^{\circ} \mathrm{C}$ decade $^{-1}$ ) occurred in the majority of the southeast.

Wind speed decreased in most catchments, ranging from $-11 \%$ decade $^{-1}$ in the southeast to $-1 \%$ decade $^{-1}$ in the upper reach of Yangtze River basin. Only five catchments showed a significant $(p<0.05)$ increase in wind. Relative humidity increased in western China (the maximum is about $3 \%$ decade $^{-1}$ ) and decreased in southeast China and the Yangtze River basin (ranging from -1.7 to $-0.5 \%$ decade $\left.^{-1}\right)$.

The change trend of relative humidity agreed with the change of precipitation, ranging from $-1.7 \%$ decade $^{-1}$ in the east to $3 \%$ decade $^{-1}$ in the west. A large increase (ranging from 2 to $3 \%$ decade $^{-1}$ ) mainly occurred in northwest
China $(p<0.05)$, while a large decrease (ranging from -1.7 to $-1 \%$ decade $\left.^{-1}\right)$ mainly occurred in the middle reach of the Yellow River basin and the Songhua River basin $(p<0.05)$.

\subsection{Contributions of climatic factors to runoff change}

Figure 6 shows the contributions of climatic factors to runoff change. The contribution of precipitation to the change in runoff has a distinct spatial variation. A positive contribution occurred in western and southeast China, especially in northwest China where the contribution of precipitation to runoff change ranges from 12 to $25 \%$ decade $^{-1}$. A negative contribution mainly occurred in central and northeast China. In the middle reaches of the Yellow River basin and the Hai River basin, the negative contribution reached the highest, ranging from -18 to $-10 \%$ decade $^{-1}$.

A positive contribution of net radiation to runoff change occurred in most catchments, except for the Qinghai-Tibet Plateau. In the Hai River basin, the positive contribution reached the highest, ranging from 3 to $9 \% \mathrm{decade}^{-1}$, compensating to some degree for the decline in runoff caused by precipitation decrease.

A negative contribution of air temperature to runoff change occurred in all of China. A large contribution $(-1$ to $-3 \%$ decade $^{-1}$ ) mainly occurred in the Songhua River basin, the Liao River basin, the Hai River basin, the lower reaches of the Yellow River basin, and the east part of the northwest area, while a small contribution $(0 \%$ to $-0.5 \%$ decade $^{-1}$ ) mainly occurred in south China.

A positive contribution of wind speed to runoff change occurred in most catchments except for part of the upper reaches of Yangtze River basin. In the Hai River basin and the Liao River basin, the positive contribution reached the highest, ranging from 2 to $6 \%$ decade $^{-1}$, compensating to some degree for the decline in runoff caused by precipitation decrease.

A negative contribution of relative humidity to runoff change occurred in most catchments except for part of northwest China where the positive contribution of relative humidity to the change of runoff ranges $0-2 \%$ decade $^{-1}$.

Figure 7 shows the dominant climatic factors driving runoff in the 207 catchments. In 143 of the total 207 catchments, the runoff change was dominated by precipitation. In addition, the runoff change was mainly determined by net radiation in some catchments of the lower reaches of the Yangtze River basin, the Pearl River basin, the Huai River basin, and the southeast area; by air temperature in the upper reaches of the Yellow River basin and the north part of the Songhua River basin; and by wind speed in part of the northeast area of Inner Mongolia. 


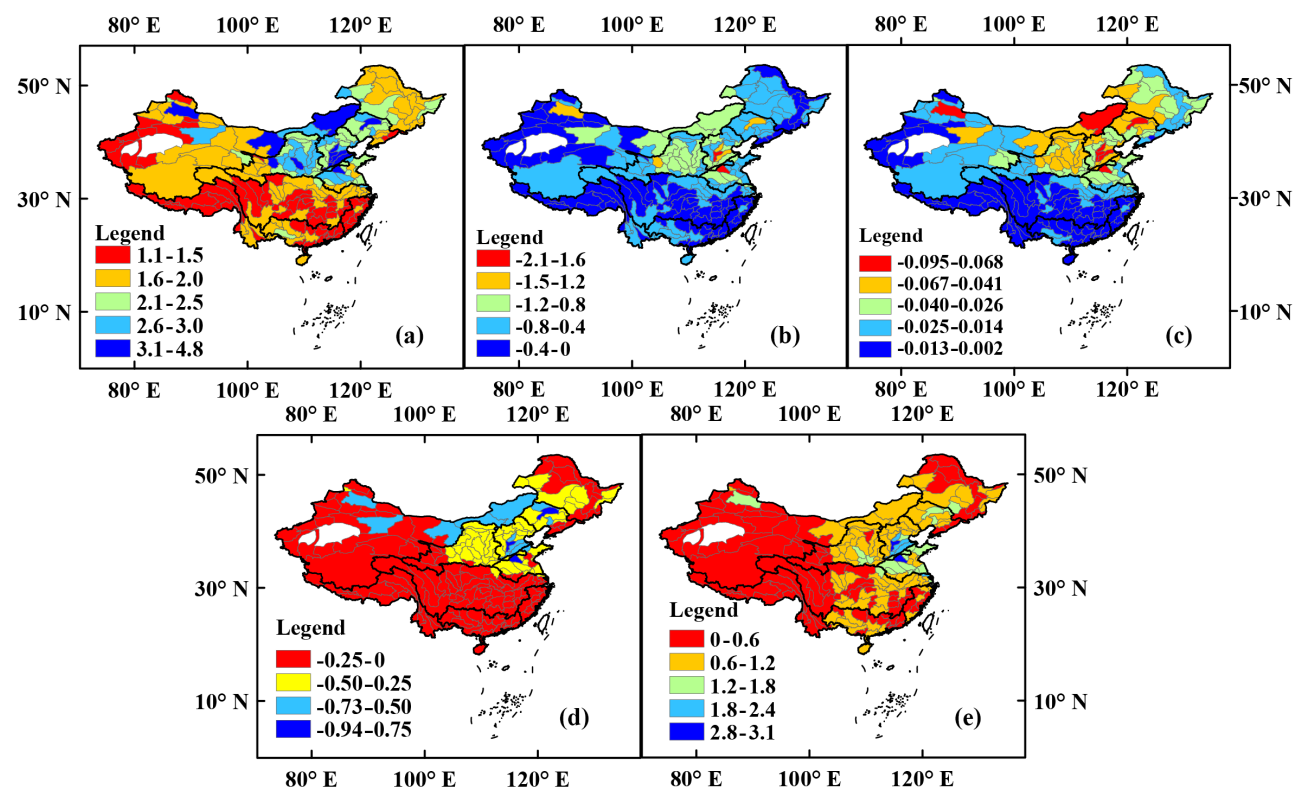

Figure 4. (a) Precipitation elasticity $\varepsilon_{\mathrm{P}}$, (b) net radiation elasticity $\varepsilon_{R_{\mathrm{n}}}$, (c) air temperature elasticity $\varepsilon_{T}$ (unit: ${ }^{\circ} \mathrm{C}$ ), (d) wind speed elasticity $\varepsilon_{U_{2}}$, and (e) relative humidity elasticity $\varepsilon_{\mathrm{RH}}$ of runoff in the 207 catchments.

\section{Discussion}

\subsection{Climate elasticity}

The climate elasticity method was widely used to evaluate the hydrologic cycle in many catchments in China. Tables 4 and 5 show the comparison of our results with estimates of climate elasticities from various references, illustrating good agreement with our results in the same regions.

\subsection{Effect of climate change on runoff}

The contribution of climatic factors to runoff change can be estimated by climate elasticity and changes in climatic factors.

The contribution of precipitation to runoff change has a regional pattern. A large negative contribution mainly occurred in the Hai River basin and the Yellow River basin, and the possible cause was the decrease in precipitation from 1961 to 2010 . This decrease may be caused by weakening of the East Asian monsoon circulation (Xu et al., 2006). However, as a result of decreasing atmospheric stability and increasing amounts of transfer of water vapor, a significant increasing trend in precipitation occurred in Xinjiang province and the Qinghai-Tibet Plateau (Bai and $\mathrm{Xu}, 2004$ ), further leading to a positive contribution of precipitation to runoff change.

A large positive contribution of net radiation occurred in the Hai River basin and the Huai River basin, while a small contribution occurred in the Qinghai-Tibet Plateau. The main cause of these results was the spatial variation of the net radiation change. As a result of atmospheric dimming and the increase of atmospheric turbidity, there was an ob- vious decrease of the surface solar radiation in China, especially in the Hai River basin and the Huai River basin (W.J. Tang et al., 2011; Zhao et al., 2006). However, due to the thin and stable air condition, net radiation in Qinghai-Tibet Plateau changed little.

There was a significant warming trend for all of China during 1961-2010 due to human activities, including industrialization and agricultural production (Ren et al., 2012), leading to a negative contribution to runoff change. Remarkably, the climate elasticity method only analyzes the direct impact of air temperature on runoff, i.e., higher temperature leading to larger evaporative demand and further inducing more evaporation (less runoff). In fact, rising temperatures also have indirect impacts on runoff (Gardner, 2009). For example, Chiew et al. (2009) reported that a degree global warming will result in $-10-3 \%$ changes in precipitation in Australia, leading to runoff change. Furthermore, rising air temperatures will lead to a longer snowmelt period, further resulting in an increase in annual runoff ( $\mathrm{Li}$ et al., 2013).

Due to the changes in atmospheric circulation and surface roughness, a weakening of wind speed has occurred in most regions of China, especially in eastern China where urbanization and environmental changes have taken place rapidly (Vautard et al., 2010; Hou et al., 2013). Consequently, the response of runoff to wind speed was intense in the Hai River basin, the Liao River basin, and the northeast area, resulting in a large positive contribution of wind speed to runoff change.

A negative contribution of relative humidity to runoff change occurred in most regions in China, caused by the trend of relative humidity change. The annual relative humid- 
Table 4. Comparison of the precipitation elasticity between the reference results and the results from this study.

\begin{tabular}{llll}
\hline Study Region & Reference & Reference results & Results from this study \\
\hline Luan River basin & Xu et al. (2013) & 2.6 & 2.5 \\
Chao-Bai River basin & Ma et al (2010) & 2.4 & 2.5 \\
Poyang Lake & Sun et al. (2013) & $1.4-1.7$ & 1.6 \\
Beijiang River catchment of the Pearl River basin & Wang et al. (2013) & 1.4 & 1.4 \\
Dongjiang River catchment of the Pearl River basin & Jiang et al. (2007) & $1.0-2.0$ & 1.4 \\
\hline
\end{tabular}

Table 5. Comparison between the runoff elasticity to climatic factors between the reference results and the results from this study.

\begin{tabular}{|c|c|c|c|c|c|c|}
\hline \multicolumn{2}{|l|}{ Study Region } & \multirow{3}{*}{$\begin{array}{l}\varepsilon_{R_{\mathrm{n}}} \\
-0.79 \\
-0.67\end{array}$} & \multirow{3}{*}{$\begin{array}{l}\varepsilon_{T} \\
-0.048 \\
-0.047\end{array}$} & \multirow{3}{*}{$\begin{array}{l}\varepsilon_{U_{2}} \\
-0.33 \\
-0.33\end{array}$} & \multirow{3}{*}{$\begin{array}{c}\varepsilon_{\mathrm{RH}} \\
0.83 \\
0.80\end{array}$} & \multirow{3}{*}{$\begin{array}{l}\text { Reference } \\
\text { Yang and Yang (2011) }\end{array}$} \\
\hline Futuo River basin & $\varepsilon^{*}$ & & & & & \\
\hline & $\varepsilon$ & & & & & \\
\hline \multirow[t]{2}{*}{ Yellow River basin } & $\varepsilon^{*}$ & -0.76 & -0.046 & -0.59 & 0.78 & \multirow[t]{2}{*}{ Tang et al. (2013) } \\
\hline & $\varepsilon$ & -1.07 to -0.46 & -0.015 to -0.067 & -0.55 to -0.1 & 0.3 to 1.1 & \\
\hline \multirow{2}{*}{$\begin{array}{l}\text { Hai River basin and } \\
\text { the Yellow River basin }\end{array}$} & $\varepsilon^{*}$ & -1.9 to -0.3 & -0.02 to -0.11 & -0.8 to -0.1 & 0.2 to 1.9 & \multirow[t]{2}{*}{ Yang and Yang (2011) } \\
\hline & $\varepsilon$ & -2.0 to 0.3 & -0.015 to -0.096 & -0.85 to -0.1 & 0.2 to 2.1 & \\
\hline
\end{tabular}

ity exhibited a reducing trend in most parts of China; one of the major causes for the reduction of relative humidity was that the increasing rates of specific humidity were smaller than those of surface saturation specific humidity with the increase of temperature (Song et al., 2012).

Precipitation is an important factor driving runoff change. Precipitation may directly impact the conditions of runoff yield or may affect the water supple conditions of evaporation and further affect runoff. Previous studies reported that precipitation decrease was the dominant factor of declining runoff in the Futuo River catchment (Yang and Yang, 2011) and the Yellow River basin (Tang et al., 2013), agreeing with our results.

In previous studies, when assessing the impacts of changes in climatic factors on runoff in China, wind speed declines were often identified as important (B. Tang et al., 2011; Liu et al., 2014; McVicar et al., 2012). Wind speed decline tended to result in the decline of actual evapotranspiration and complementary increase of streamflow in wet river basins but had little impacts in dry basins (Liu et al., 2014), similar to our results. Remarkably, in some catchments of the northeast area and Inner Mongolia, declining wind speed had the greatest contribution to runoff change. In these catchments, changes in precipitation were minimal and the contribution of precipitation to runoff change was small compared with that of wind speed.

The runoff change was mainly determined by net radiation in some catchments of the lower reaches of the Yangtze River basin, the Pearl River basin, the Huai River basin, and the southeast area, and by air temperature in the upper reaches of the Yellow River basin and the north part of the Songhua
River basin. In these catchments, the precipitation elasticity was low; the changes were slight; and the contribution of precipitation to runoff was small. However, due to a significant decreasing trend in net radiation or obvious warming, changes in net radiation or air temperature had greater impacts on runoff compares with precipitation.

Remarkably, for a specific catchment, some climatic factors have a positive contribution to runoff, while others have a negative contribution. For example, in the Hai River basin, decreasing precipitation lead to a change in runoff from -8 to $-18 \%$ decade $^{-1}$; at the same time, declining net radiation caused a 2-9\% decade ${ }^{-1}$ runoff change, and weakening wind speed caused a $1.5-4.5 \%$ decade $^{-1}$ runoff change, compensating for the runoff decline caused by decreasing precipitation. Consequently, the runoff decrease due to climate change is $0-9 \%$ decade $^{-1}$ (Yang et al., 2014a). Conversely, in the middle reaches of the Yellow River basin, decreasing precipitation also has a contribution to runoff from -8 to $-18 \%$ decade $^{-1}$, but the positive contributions from net radiation and wind speed are less than those in the Hai River basin, which leads to the largest runoff decline, 5$13 \%$ decade $^{-1}$, in the Hai River basin (Yang et al., 2014a).

The dominant climatic factor driving runoff change was determined by the geographic conditions and climate change. In this study, we analyzed the contribution of climatic factors to runoff change by the climate elasticity method. This method only focused on the direct impact of climate change on runoff but ignored the interaction among the climatic factors. These interactions need further study. 


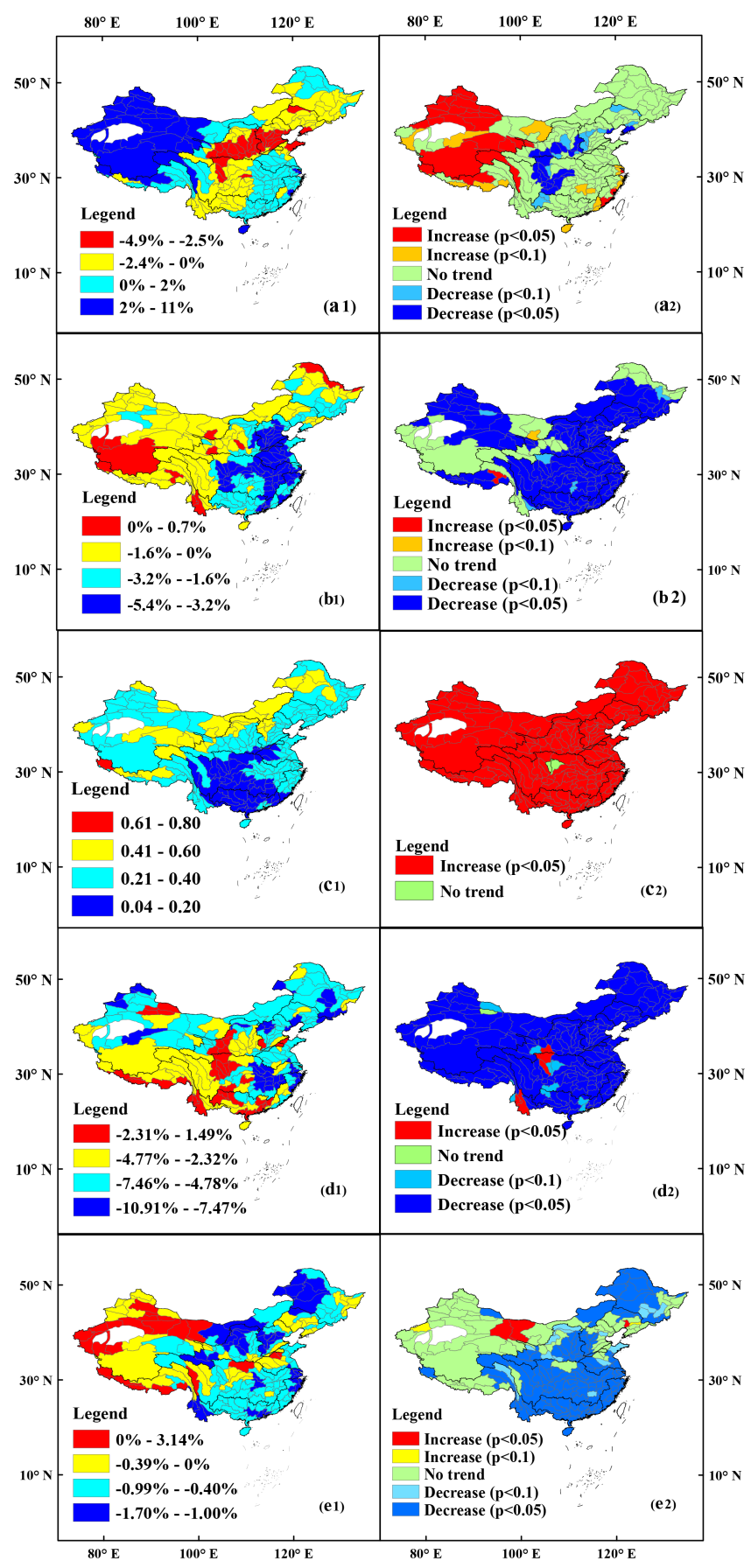

Figure 5. The changing trends for (a1) precipitation (unit: decade $^{-1}$ ), (b1) net radiation (unit: decade ${ }^{-1}$ ), (c1) air temperature (unit: ${ }^{\circ} \mathrm{C}$ decade $^{-1}$ ), (d1) wind speed (unit: decade ${ }^{-1}$ ), (e1) relative humidity (unit: decade ${ }^{-1}$ ); and the significance of the trends for (a2) precipitation, (b2) net radiation, (c2) air temperature, (d2) wind speed, (e2) relative humidity to runoff in the 207 catchments from 1961 to 2010.

\subsection{Error analysis}

In Eq. (10), the net radiation $R_{\mathrm{n}}$ and the air temperature $T$ were considered as two independent variables. However, according to Eqs. (12) and (13), the net radiation $R_{\mathrm{n}}$ is associated with the air temperature $T$. To verify the impact of the relationship between net radiation and air temperature on Eq. (12), the effect of the change in air temperature to change in net radiation $R_{\mathrm{n}}$ must be evaluated as follows:

$d R_{\mathrm{n}}=\frac{\Delta R_{\mathrm{n}}}{\Delta T} \mathrm{~d} T$.

If the effect of $T$ on $R_{\mathrm{n}}$ is ignored, the relative error has been observed to be less than $1 \%$, as evaluated by Yang and Yang (2011) in the Futuo River basin.

In addition, Eq. (10) is a first-order approximation, probably resulting in errors in the estimating of climate elasticity. Yang et al. (2014a, b) evaluated that when the changes in potential evapotranspiration $\left(\Delta E_{0}\right)$ and precipitation $(\Delta P)$ are not large, the error of $\varepsilon_{\mathrm{P}}$ caused by first-order approximation can be neglected, but the error will increase with increasing changes with a $0.5-5 \%$ relative error in $\varepsilon \mathrm{P}$ when $\Delta P=10 \mathrm{~mm}$ and a $5-50 \%$ relative error in $\varepsilon \mathrm{P}$ when $\Delta P=$ $100 \mathrm{~mm}$.

\section{Conclusion}

In this study, we used the climate elasticity method to reveal the dominant climatic factor driving annual runoff change across China. We first validated the climate elasticity method that was first derived by Yang and Yang (2011). On account of China being a vast country with remarkable spatial differences in climate and geographical characteristics, we divided China into 207 catchments, evaluated the climate elasticity of runoff relative to precipitation, net radiation, air temperature, wind speed and relative humidity, and estimated the contribution of climatic factors to runoff change for each catchment.

In the 207 catchments, precipitation elasticity, which was low in southern China and part of the northwest area, and high in the Liao River basin, the Hai River basin, and the Huai River basin, ranged from 1.1 to 4.8 (2.0 on average). This elasticity means that a $1 \%$ change in precipitation will lead to a $1.1-4.8 \%$ change in runoff. The air temperature elasticity, which ranged from -0.002 to $-0.095^{\circ} \mathrm{C}^{-1}$ $\left(-0.025^{\circ} \mathrm{C}^{-1}\right.$ on average), net radiation elasticity, which ranged from -0.1 to -2 ( -0.5 on average), wind speed elasticity, which ranged from -0.01 to 0.94 ( -0.22 on average), and relative humidity elasticity, which ranged from 0.05 to 3 ( 0.74 on average), had similar distributions to precipitation elasticity.

A large negative contribution of precipitation to runoff change mainly occurred in the Hai River basin and the Yellow River basin, while a positive contribution occurred in Xinjiang province and the Qinghai-Tibet Plateau. A large 


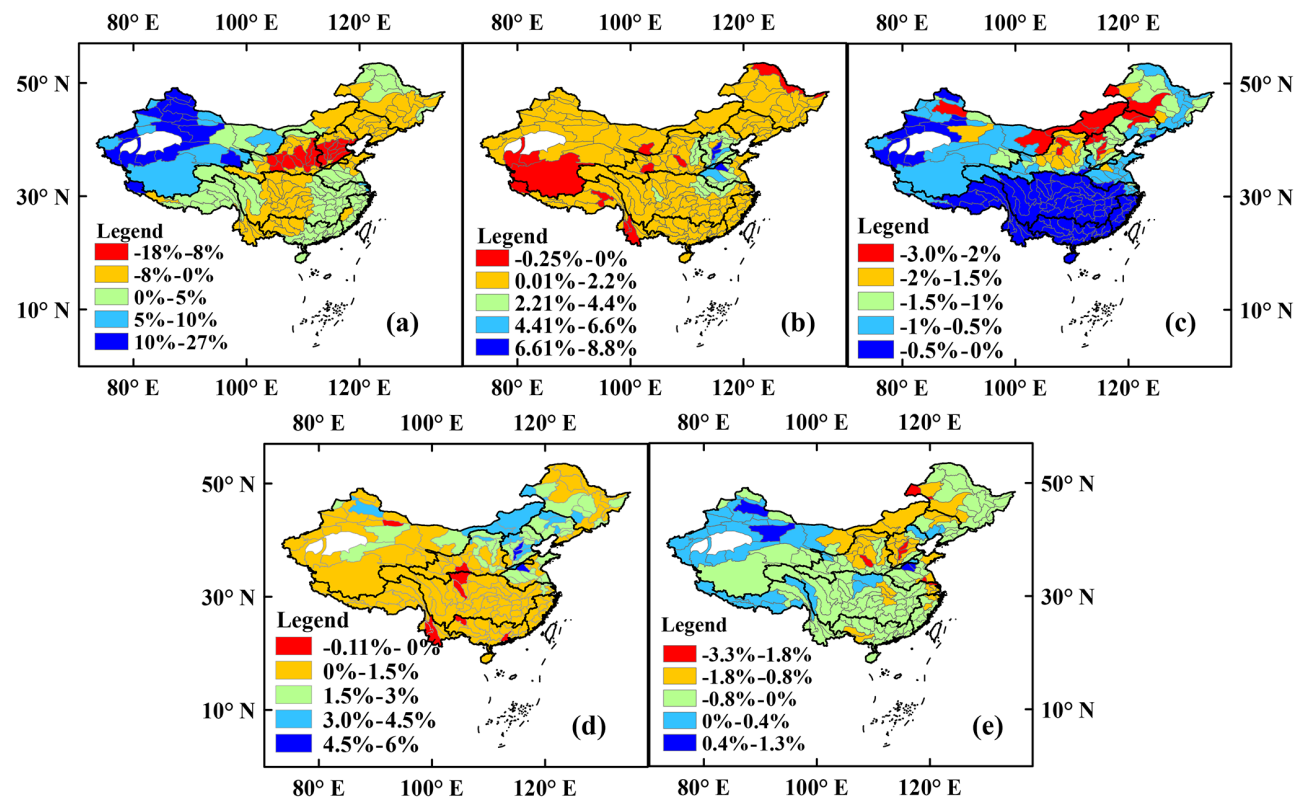

Figure 6. The contribution of (a) precipitation, (b) net radiation, (c) air temperature, (d) wind speed, and (e) relative humidity to runoff change in the 207 catchments from 1961 to 2010 (unit: decade).

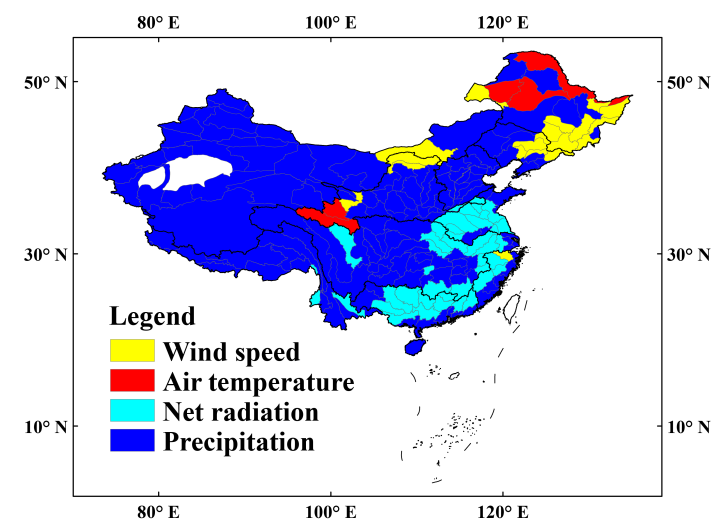

Figure 7. Dominant climatic factors driving annual runoff change in the 207 catchments from 1961 to 2010.

positive contribution of net radiation occurred in the Hai River basin and the Huai River basin, while a small contribution occurred in the Qinghai-Tibet Plateau. A negative contribution of air temperature to runoff change occurred in all of China. A positive contribution of wind speed to runoff change occurred in most parts of China, while a negative contribution of relative humidity to runoff change occurred in most regions of China. A $5-13 \%$ decade $^{-1}$ decrease in runoff was caused by climate change in the middle reaches of the Yellow River basin and the Hai River basin (Yang et al., 2014a). Specifically, changes in precipitation, air temperature, and relative humidity contributed negative impacts on runoff. Simultaneously, declines in net radiation and wind speed had positive impacts on runoff, slowing the overall decline in runoff.

Precipitation was the dominant climatic factor driving runoff change in most of the 207 catchments. Net radiation was dominant in some catchments of the lower reaches of the Yangtze River basin, the Pearl River basin, the Huai River basin, and the southeast area; air temperature was dominant in the upper reaches of the Yellow River basin and the north part of the Songhua River basin; and wind speed was dominant in part of the northeast area of Inner Mongolia. 


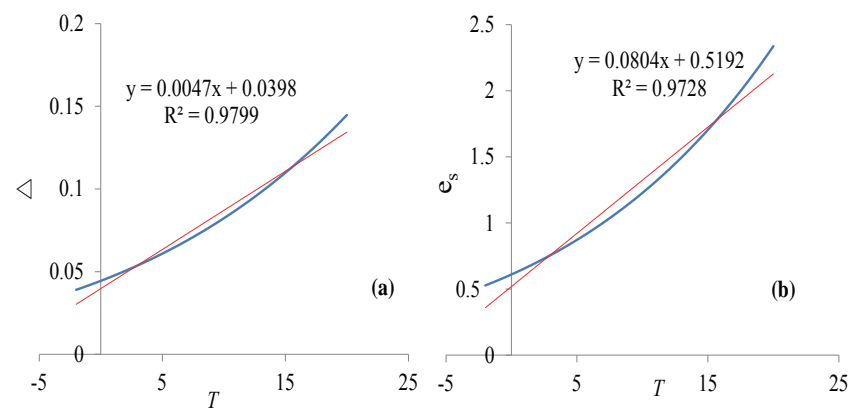

Figure A1. The relationship of (a) $\left(\mathrm{kPa}^{\circ} \mathrm{C}^{-1}\right)$ and (b) $e_{\mathrm{S}}(\mathrm{kPa})$ with temperature $T\left({ }^{\circ} \mathrm{C}\right)$ change. The blue curves are the relationship of and $e_{\mathrm{S}}$ with $T$, respectively; the pink curves show the linear slope of and $e_{\mathrm{S}}$ with $T$ ( $T$ ranging from -2 to $20^{\circ} \mathrm{C}$ ), respectively.

\section{Appendix A: The air temperature elasticity}

The air temperature elasticity ranged from -0.002 to $-0.095^{\circ} \mathrm{C}^{-1}$, which was obviously smaller compared with other climatic elasticities. To explore the causes, air temperature elasticity was calculated by the following equation:

$\varepsilon_{T}=\varepsilon_{2} \varepsilon_{4}=\left.\varepsilon_{2} \frac{1}{\overline{E_{0}}} \frac{\partial E_{0}}{\partial T}\right|_{X=\bar{X}}$,

where $\varepsilon_{2}$ was the runoff elasticity to potential evaporation, ranging from -3 to 0 in China. Next, we analyzed the value of $\frac{\partial E_{0}}{\partial T}$ by the differential method. Denoting Eq. (8) as $E_{0}=f_{1}\left(\Delta, e_{\mathrm{s}}\right)$, we can express $\left(\mathrm{kPa}^{\circ-1}\right)$ and $e_{\mathrm{S}}(\mathrm{kPa})$ as $\Delta=f_{2}(T)$ and $e_{\mathrm{S}}=f_{3}(T)$, respectively. Due to their substitution, $\frac{\partial E_{0}}{\partial T}$ can be expressed as

$\frac{\partial E_{0}}{\partial T}=\frac{\partial E_{0}}{\partial \Delta} \frac{\partial \Delta}{\partial T}+\frac{\partial E_{0}}{\partial e_{\mathrm{s}}} \frac{\partial e_{\mathrm{s}}}{\partial T}$

where $\frac{\partial E_{0}}{\partial \Delta}=\frac{\gamma}{(\Delta+\gamma)^{2}}\left[\frac{\left(R_{\mathrm{n}}-G\right)-6.43\left(1+0.536 U_{2}\right)(1-\mathrm{RH}) e_{\mathrm{s}}}{\lambda}\right]$ and $\frac{\partial E_{0}}{\partial e_{\mathrm{s}}}=\frac{\gamma}{\Delta+\gamma} 6.43\left(1+0.536 U_{2}\right)(1-\mathrm{RH}) / \lambda$. Figure A1 shows the trend of and $e_{\mathrm{s}}$ as the change in temperature according to the relationship between $\Delta$ and $T$ and between $e_{\mathrm{S}}$ and $T$, where the average values of $\frac{\partial \Delta}{\partial T}$ and $\frac{\partial e_{\mathrm{s}}}{\partial T}$ were 0.0047 and 0.08 in the 207 catchments, respectively. Figure A2a and show the relationship of $\frac{\partial E_{0}}{\partial \Delta}$ and $\frac{\partial E_{0}}{\partial e_{\mathrm{s}}}$ with $T$ in 207 basins of China. $\frac{\partial E_{0}}{\partial \Delta}$ ranged from -5.5 to 9.3 ( 0.22 on average), while $\frac{\partial E_{0}}{\partial e_{\mathrm{s}}}$ which ranged from 0.3 to 1.9 ( 0.85 on average), decreased with rising air temperature. From the results above, it can be found that the absolute value of $\frac{\partial E_{0}}{\partial \Delta} \frac{\partial \Delta}{\partial T}$ was small when compared with $\frac{\partial E_{0}}{\partial e_{\mathrm{S}}} \frac{\partial e_{\mathrm{S}}}{\partial T}$ due to the small value of $\frac{\partial \Delta}{\partial T}$. $\frac{\partial E_{0}}{\partial T}$ was mainly determined by $\frac{\partial E_{0}}{\partial e_{\mathrm{s}}}$, indicating that the rising air temperature mainly affected saturation vapor pressure, leading to changes in potential evaporation. Based on the results, Figure A3 shows the relationship between $T$ and $\frac{\partial E_{0}}{\partial T}$ in 207 basins of China. $\frac{\partial E_{0}}{\partial T}$ ranged from 0.04 to 0.12 in different basins, a decreasing trend as $T$ increased. 

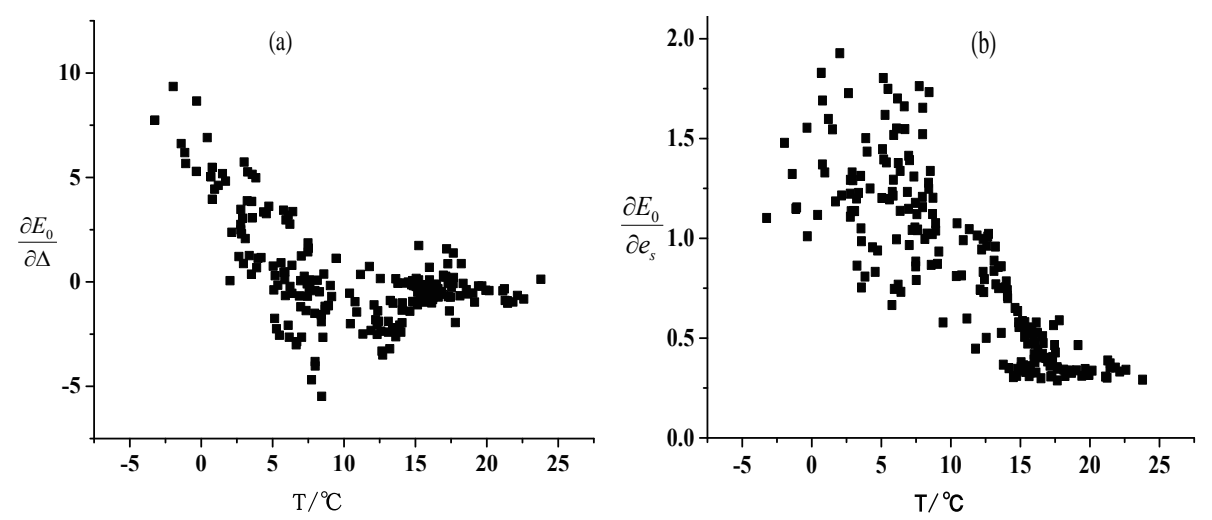

Figure A2. The relationship of (a) $\frac{\partial E_{0}}{\partial \Delta}$ and (b) $\frac{\partial E_{0}}{\partial e_{\mathrm{s}}}$ with $T$, respectively, in the 207 basins of China.

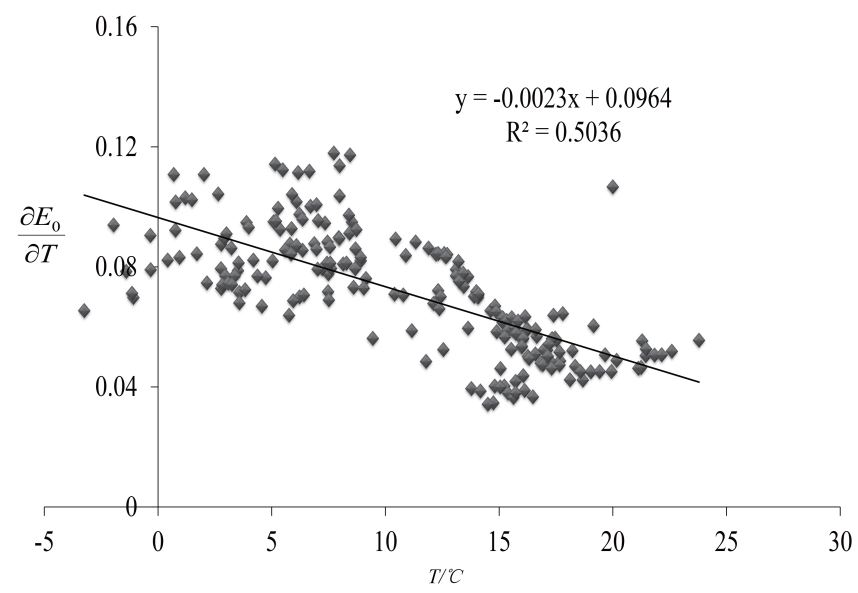

Figure A3. The relationship between $\frac{\partial E_{0}}{\partial T}$ and $T$ in the 207 basins of China. 
Acknowledgements. This research was partially supported by funding from the National Natural Science Foundation of China (nos. 51379098 and 91225302) and the National Program for Support of Top-notch Young Professionals. In addition, this research benefited from the China Meteorological Data Sharing Service System, which provided the meteorological data. We are grateful to the editor, Hongyi Li, as well as Maik Renner, Mishra Ashok, and another anonymous referee for helpful comments.

Edited by: H. Li

\section{References}

Allen, R., Pereira, L., Raes, D., and Smith, M.: Crop evapotranspiration: guidelines for computing crop water requirements. FAO Irrigation and Drainage Paper 56, FAO, Rome, 300, D05109, 1998.

Angström, A.: Solar and terrestrial radiation, Q. J. Roy. Meteorol. Soc., 50, 121-126, 1924.

Arnold, J. G. and Fohrer, N.: SWAT2000: current capabilities and research opportunities in applied watershed modelling, Hydrol. Process., 19, 563-572, doi:10.1002/hyp.5611, 2005.

Arnold, J. G., Srinivasan, R., Muttiah, R. R., and Williams, J. R.: Large hydrologic modeling and assessment Part 1: Model development, J. Am. Water Resour. Assoc, 34, 73-89, doi:10.1111/j.1752-1688.1998.tb05961.x, 1998.

Arora, V. K.: The use of the aridity index to assess climate change effect on annual runoff, J. Hydrol., 265, 164-177, doi:10.1007/BF02873094, 2002.

Bai, J. and Xu, X.: Atmospheric hydrological budget with its effects over Tibetan plateau, J. Geograph. Sci., 14, 81-86, doi:10.1080/00385417.1961.10770761, 2004.

Budyko, M. I.: The Heat Balance of the Earth's Surface, Soviet Geograph., 2, 3-13, 1961.

Chiew, F., Teng, J., Vaze, J., and Kirono, D.: Influence of global climate model selection on runoff impact assessment, J. Hydrol., 379, 172-180, doi:10.1016/j.jhydrol.2009.10.004, 2009.

Cong, Z., Yang, D., Gao, B., Yang, H., and Hu, H.: Hydrological trend analysis in the Yellow River basin using a distributed hydrological model, Water Resour. Res., 45, 335-345, doi:10.1029/2008WR006852, 2009.

Fu, G., Charles, S. P., and Chiew, F. H. S.: A two-parameter climate elasticity of streamflow index to assess climate change effects on annual streamflow, Water Resour. Res., 43, W11419, doi:10.1029/2007WR005890, 2007.

Gardner, L. R.: Assessing the effect of climate change on mean annual runoff, J. Hydrol., 379, 351-359, doi:10.1016/j.jhydrol.2009.10.021, 2009.

Hou, A., Ni, G., Yang, H., and Lei, Z.: Numerical analysis on the contribution of urbanization to wind stilling: an example over the Greater Beijing Metropolitan area, J. Appl. Meteorol. Climatol., 52, 1105-1115, doi:10.1175/JAMC-D-12-013.1, 2013.

Jiang, T., Chen, Y. D., Xu, C. Y., Chen, X., Chen, X., and Singh, V. P.: Comparison of hydrological impacts of climate change simulated by six hydrological models in the Dongjiang Basin, South China, J. Hydrol., 336, 316-333, doi:10.1016/j.jhydrol.2007.01.010, 2007.

Kendall, M. G.: Rank correlation methods, Biometrika, 1948.
Kendall, M. G.: Rank Correlation Methods, Oxford University Press, Oxford, 1990.

Li, B., Chen, Y., Chen, Z., Li, W., and Zhang, B.: Variations of temperature and precipitation of snowmelt period and its effect on runoff in the mountainous areas of Northwest China, J. Geograph. Sci., 23, 17-30, doi:10.1007/s11442-013-0990-1, 2013.

Liu, X., Zhang, X.-J., Tang, Q., and Zhang, X.-Z.: Effects of surface wind speed decline on modeled hydrological conditions in China, Hydrol. Earth Syst. Sci., 18, 2803-2813, doi:10.5194/hess-18-2803-2014, 2014.

Ma, H., Yang, D., Tan, S. K., Gao, B., and Hu, Q.: Impact of climate variability and human activity on streamflow decrease in the Miyun Reservoir catchment, J. Hydrol., 389, 317-324, doi:10.1016/j.jhydrol.2010.06.010, 2010.

Ma, Z., Kang, S., Zhang, L., Tong, L., and Su, X.: Analysis of impacts of climate variability and human activity on streamflow for a river basin in arid region of Northwest China, J. Hydrol., 352, 239-249, doi:10.1016/j.jhydrol.2007.12.022, 2008.

Maidment, D. R.: Handbook of Hydrology, McGraw-Hill, New York, 224-227, 1993.

Mcvicar, T. R., Roderick, M. L., Donohue, R. J., and Van Niel, T. G.: Less bluster ahead? Ecohydrological implications of global trends of terrestrial near-surface wind speeds, Ecohydrology, 5, 381-388, doi:10.1002/eco.1298, 2012.

Mou, L., Tian, F., Hu, H., and Sivapalan, M.: Extension of the Representative Elementary Watershed approach for cold regions: constitutive relationships and an application, Hydrol. Earth Syst. Sci., 12, 565-585, doi:10.5194/hess-12-565-2008, 2008.

Penman, H. L.: Natural evaporation from open water, Bare Soil and Grass, Roy. Soc. Lnd. Proc., 193, 120-145, 1948.

Ren, G., Ding, Y., Zhao, Z., Zheng, J.,Wu, T., Tang, G. and Xu, Y.: Recent progress in studies of climate change in China, Adv Atmos Sci, 29, 958-977, doi:10.1007/s00376-012-1200-2, 2012.

Sankarasubramanian, A., Vogel, R. M., and Limbrunner, J. F.: Climate elasticity of streamflow in the United States, Water Resour. Res., 37, 1771-1781, doi:10.1029/2000WR900330, 2001.

Schaake, J. C.: From climate to flow, Climate change and US water resources., edited by: Waggoner, P. E., John Wiley, New York, 177-206, 1990.

Song, Y., Liu, Y., and Ding, Y.: A study of surface humidity changes in china during the recent 50 years, Acta Meteorologica Sinica, 26, 541-553, doi:10.1007/s13351-012-0501-9, 2012.

Sun, S., Chen, H., Ju, W., Song, J., Zhang, H., Sun, J., and Fang, Y.: Effects of climate change on annual streamflow using climate elasticity in Poyang Lake Basin, China, Theor. Appl. Climatol., 112, 169-183, doi:10.1007/s00704-012-0714-y, 2013.

Sun, Y., Tian, F., Yang, L., and Hu, H.: Exploring the spatial variability of contributions from climate variation and change in catchment properties to streamflow decrease in a mesoscale basin by three different methods, J. Hydrol., 508, 170-180, doi:10.1016/j.jhydrol.2013.11.004, 2014.

Tang, B., Tong, L., Kang, S., and Zhang, L.: Impacts of climate variability on reference evapotranspiration over 58 years in the Haihe river basin of north China, Agr. Water Manage., 98, 16601670, doi:10.1016/j.agwat.2011.06.006, 2011.

Tang, Q., Oki, T., Kanae, S., and Hu, H.: The influence of precipitation variability and partial irrigation within grid cells on a hydrological simulation, J. Hydrometeorol., 8, 499-512, 2007. 
Tang, W.-J., Yang, K., Qin, J., Cheng, C. C. K., and He, J.: Solar radiation trend across China in recent decades: a revisit with quality-controlled data, Atmos. Chem. Phys., 11, 393-406, doi:10.5194/acp-11-393-2011, 2011.

Tang, Y., Tang, Q., Tian, F., Zhang, Z., and Liu, G.: Responses of natural runoff to recent climatic variations in the Yellow River basin, China, Hydrol. Earth Syst. Sci., 17, 4471-4480, doi:10.5194/hess-17-4471-2013, 2013.

Tian, F., Hu, H., Lei, Z., and Sivapalan, M.: Extension of the Representative Elementary Watershed approach for cold regions via explicit treatment of energy related processes, Hydrol. Earth Syst. Sci., 10, 619-644, doi:10.5194/hess-10-619-2006, 2006.

Vautard, R., Cattiaux, J., Yiou, P., Thepaut, J. and Ciais, P.: Northern Hemisphere atmospheric stilling partly attributed to an increase in surface roughness, Nat Geosci, 3, 756-761, doi:10.1038/ngeo979, 2010.

Vogel, R. M., Wilson, I., and Daly, C.: Regional regression models of annual streamflow for The United States, J. Irr. Drain. Eng., $125,148-157,1999$.

Wang, Z., Shen, Y., and Song, L.: Hydrologic response of the climatic change based on SWAT Model in Beijiang River basin, Meteorol. Environ. Res., 8-12, 2013.

Water Resources and Hydropower Planning and Design General Institute, Specification for Comprehensive Water Resources Zoning, China Water \& Power Press, Beijing China, 2011.

Xu, M., Chang, C., Fu, C., Qi, Y., Robock, A., Robinson, D., and Zhang, H.: Steady decline of east Asian monsoon winds, 19692000: evidence from direct ground measurements of wind speed, J. Geophys. Res., 111, doi:10.1029/2006JD007337, 2006.

$\mathrm{Xu}$, X., Yang, H., Yang, D., and Ma, H.: Assessing the impacts of climate variability and human activities on annual runoff in the Luan River basin, China, Hydrol. Res., 44, 940-952, doi:10.2166/nh.2013.144, 2013.

Yang, D., Herath, S., and Musiake, K.: Development of geomorphology-based hydrological model for large catchments, Proc. Hydraul. Eng., 42, 169-174, 1998.

Yang, D., Herath, S., and Musiake, K.: Comparison of different distributed hydrological models for characterization of catchment spatial variability, Hydrol. Process., 14, 403-416, 2000.
Yang, D., Li, C., Hu, H., Lei, Z., Yang, S., Kusuda, T., Koike, T., and Musiake, K.: Analysis of water resources variability in the Yellow River of China during the last half century using historical data, Water Resour. Res., 40, 308-322, doi:10.1029/2003WR002763, 2004.

Yang, D., Sun, F., Liu, Z., Cong, Z., and Lei, Z.: Interpreting the complementary relationship in non-humid environments based on the Budyko and Penman hypotheses, Geophys. Res. Lett., 33, 122-140, doi:10.1029/2006GL027657, 2006.

Yang, H. and Yang, D.: Derivation of climate elasticity of runoff to assess the effects of climate change on annual runoff, Water Resour. Res., 47, 197-203, doi:10.1029/2010WR009287, 2011.

Yang, H., Yang, D., Lei, Z., and Sun, F.: New analytical derivation of the mean annual water/energy balance equation, Water Resour. Res., 44, 893-897, doi:10.1029/2007WR006135, 2008.

Yang, H., Qi, J., Xu, X., Yang, D., and Lv, H.: The regional variation in climate elasticity and climate contribution to runoff across China, J. Hydrol., 517, 607-616, doi:10.1016/j.jhydrol.2014.05.062, 2014a.

Yang, H., Yang, D., and Hu, Q.: An error analysis of the Budyko hypothesis for assessing the contribution of climate change to runoff, Water Resour. Res., 50, 9620-9629, doi:10.1002/2014WR015451, 2014b.

Yang, H., Yang, D., Hu, Q., and lv, H.: Spatial variability of the trends in climatic variables across China during 1961-2010, Theor. Appl. Climatol., 120, 773-783, doi:10.1007/s00704-0141208-x, 2015.

Zhao, C., Tie, X., and Lin, Y.: Apossible positive feedback of reduction of precipitation and increase in aerosols over eastern central China, Geophys Res Lett, 33, L11814, doi:10.1029/2006GL025959, 2006.

Zheng, H., Zhang, L., Zhu, R., Liu, C., Sato, Y., and Fukushima, Y.: Responses of streamflow to climate and land surface change in the headwaters of the Yellow River Basin, Water Resour. Res., 45, W00A19, doi:10.1029/2007WR006665, 2009. 